\title{
The Firm as a Viable System
}

\author{
Gaetano M. Golinelli ${ }^{*}$ Mauro Gatti**
}

\begin{abstract}
The viable system logic is widely considered a reference point for all the entrepreneurial organizations.

The viable organizations have to struggle for existence, a statement particularly valid, if we consider changes (adjustments, transformations, reorganizations) of logic and physical assets (logic and physical structure) as also specific configurations developed in time.

As a consequence, a viable system can be defined as follows: it is a system that survives, remains united and entire; it is omeostatically equilibrated internally and externally; it contains mechanisms and opportunities to grow, learn, develop and adapt becoming more efficient in a proper context
\end{abstract}

Keywords: Firm; Systemic Approach; Management Studies; Viable System, Market-Driven Management

\section{Systemic Approach and Management Studies}

The purpose of the following paper is to analyze how does the systemic approach contribute to understanding different points of view as well as to grasp the nature of relationships emerged between the firm and its interlocutors. Among a large number of systemic approach benefits we can pinpoint its ability to represent firms evolution dynamics in an efficient manner. All the more so in the modern context, where firms development processes are always more influenced by relationship management that links the firm with numerous local entities. Thus, since the companies have to struggle for survival, a remarkable stress has been put on both: adequacy and coherence between structural configuration and prefigured objectives. Moreover, a systems structural openness has proved its relevance in a proper business-model enhancement and in a competitive position improvement (value generation in time). Naturally, in such condition the firm evolves parallel to the context it operates in.

The methodological approach proposed in this paper recalls a 'viable system' concept, conveniently revisited in order to assure a greater coherence with an observational perspective, in our case - the management's perspective ${ }^{1}$. The

\footnotetext{
"Full Professor of Management, University of Rome-La Sapienza (gaetano.golinelli@uniroma1.it)

** Associate Professor of Management, University of Milan-Bicocca (mauro.gatti@ unimib.it)
}

Golinelli Gaetano M., Gatti Mauro, The Firm as a Viable System, Symphonya. Emerging Issues in Management (symphonya.unimib.it), n. 2, 2000-2001, pp. 38-63 
purpose then, is to recall the attention on aspects directly related to a suitable approach.

\subsection{Concepts Supporting the Systemic Approach in Management Studies}

\section{a) From the Structure to the System}

In order to guarantee better firms evolution comprehension it is necessary to observe diverse stages that portray the passage from the structure to the system. In reference to the firms system structure we can distinguish:

- a 'logic structure', meant as all the 'logic components' suitable for a specific role execution, in respect to rules and particular relationships with other components;

- a 'physical structure', in other words, all the 'physical components', the function and application of which, are widely known and recognized;

- a passage from the 'logic structure' to the physical one recalls a 'project' existence. In other words, it is about a logic schematization ('organizational scheme') that, even before its physical materialization, tries to foresee which elements and logic components are required for a specific structure and what logic relations they should involve to allow the correct system implementation.

Thus, a 'system' is a physical structure provided with physical components meant as a predefined and interacting logic components qualification, based on a specific purpose orientation. The structure expresses the ability to reach the goal through an adequate aim-oriented behavior. The structure in action, that is a common aim-oriented structure, represents the system.

The passage from the structure to the system, then, is commonly qualified in terms of a structure's system 'emergency', where:

1. a system's objective has been recognized and, as a consequence, a complex of goals to achieve by the structure;

2. specific roles have been assigned to diverse structural components, rigorously coherent to the fallowing objective;

3. interrelations between structural components and the structure itself, but also between other systems in action.

As far as the passage from the structure to the system evokes a dynamic aspect, its representation, static by definition, encounters a number of limits. In other words, the dynamic conceptual interpretation can be undertaken only through a static description. In fact, every attempt of representing the system brings inevitably to the structure representation ${ }^{2}$.

\section{b) Relations and Interrelations}

In order to define the structure and the system two terms have been commonly used: relation and interrelation. In fact, focus on the structure involves numerous logic and physical connections, that allow the components to act in a mutual manner, to generate synergies and, finally, to act in virtue of common objectives. 
Thus, the relation is a logic or physical connection between the structure components. The system, on the other hand, recalls attention on the moment of interaction - that is, on the phase where the components exchange resources and share their know-how in order to achieve a common goal.

The (structural) relation concept evokes a static aspect and qualifies itself as objective. The (systemic) interaction, on the contrary, evokes a dynamic spirit and assumes a subjective nature as far as it depends not only on the system, but firstly on the observer, on what he can deduce from the analysis.

\section{c) The Expanded Structure}

Till now, a 'static' representation has imposed a conceptual centrality of physical structure. It is necessary, however, to contemplate its 'dynamic' nature and to do so, the 'system openness' concept reveals essential ${ }^{3}$. The firm system, equipped with an adequate physical structure, need to consider the possibility of collaborating with external organizations that can be seen as systems provided with different physical structures. As a result, it is necessary to envisage two fundamental conditions, useful for better system representation:

- in some way the firm system should interact with external context and, consequently, reinforce relations between internal and external components that involve physical structures of different systems;

- after defining objectives to obtain, the management should select processes qualifying all the activities oriented on generating relations between internal and external components. In particular, such activities should consider not only physical limitations related to internal components characteristics, but also behavioral regulations deriving from modalities and standards imposed by the external context looking for a consonance and resonance ${ }^{4}$.

\section{d) Organizational Scheme Concept}

It becomes clear that the 'organizational scheme' qualifies guide-lines for a dynamic structure implementation, analyzed as follows. In fact, the organizational scheme is largely meant as activities and processes design, implemented through a sequence of relations between internal components, interacting among each other but also with external components.

If we reason in an entrepreneurship logic, the governance is up to design a map of possible interactions among internal components but also among internal and some of external components (individuated in accordance to a logic profile). Thus, it is exactly the organizational scheme notion to mark a conceptual, logic shift from the 'structure tangibility' to the 'system intangibility'. The governance allows the firm system to emerge through expanded structure dynamism and, consequently, to adjust the organizational scheme.

The organizational scheme comprehension requests, however, two specific concepts detection:

a) provisional organizational scheme;

b) defined organizational scheme. 
Both notions refer to two different moments in the passage from the entrepreneurship idea to the firm system.

The first phase recalls the passage from the entrepreneurship idea to the logic structure across the intermediate phase of provisional organizational scheme. The following phase, to be more precise, regards questions like 'who does what? How? When?'. These questions, in particular, induce to reflect on the first, 'embryonic' components and relations (also with the external context) determination. It's about an unavoidable and essential passage oriented on a logic structure specification that, in the light of a provisional organizational scheme, implements a number of adequate roles and relationships that naturally respect the scheme's requirements. Such variety of roles and relationships has to contemplate also all the connections demanded afterwards, that is in the moment of expanded structure implementation, qualifying the system interaction with an external context.

The second phase enacts once the physical structure is realized and the system has emerged (the physical structure ready to interact with an external context). In this case, the governance defines expanded structure through the organizational scheme determination. Moreover, there are numerous factors that enable the structure identification. The governance, for instance, has to reckon with the physical structure realized respect to desired logic structure (defined exactly by provisional organizational scheme). However, some adjustments referable to physical components can be retained necessary. Subsequently, the governance has to consider different external interlocutors characteristics (like other companies, institutions etc.) with whom the firm system interacts directly through its physical structure. As a result, some internal relationships can result insufficient respect to external connections required ${ }^{5}$.

\subsection{Systemic Approach in the Governance Perspective}

The logic, physical, expanded structures and provisional, defined organizational scheme notions qualify the conceptual matrix outlined in this paper. Moreover, the ambition of the following study is to emphasize the dynamic aspect represented by interactions, processes and the firm system itself. It is necessary then to expand these concepts on the entrepreneurship phenomenon, observing the impact of decision making subjects - board of directors in particular - on the firm system. In order to give a greater consistency and development perspectives to the firm system, a continuous planning activity (performed by an adequate organs nominated by the top management) is essential.

The first phase consists in entrepreneurship idea specification. It's about a complex process which originates decisions of firms foundation and, subsequently, of competitive features development in order to make the offering system more attractive to potential consumers and surely profitable. Secondly, it is necessary to define the provisional organizational scheme, which contains first design definition. To be more precise, the following scheme is a reference point for specific logic components, conveniently identified and interconnected in virtue of output generation and collocation on the market. From the following considerations springs the logic structure notion. The logic structure finds its concrete application in a specific physical structure, that contains physical components and connection relationships between them. Such conceptual shift qualifies the expanded structure and origins an abandonment of internal logic in favor of new perspective 
assumption that foresees the physical structure dynamism respect to the external context. In the light of this statement, the expanded structure summarizes not only physical qualities of internal components (and relationships between them) but also the governance choices and decisions, aspiring to qualify the emerging system.

The governance is essentially called to combine in a dynamic manner all the abilities integrated to the structural components (in other words, all the abilities related to pre-existing technical and technological skills as also all the experience generated in time) with an informative variety: a variety (innovations, possible solutions etc.) which requests a further screening accomplished by the top management.

Such conceptual layout qualifies a further firm modeling in a systemic logic, widely shared and sustained by numerous authors. Once a firm is retained a system, it becomes necessary to identify its 'propulsive' force, represented obviously by all decision-making subjects, in particular, by the firm's top management. Consequently, a necessity of systemic model that emphasizes such figures has risen; a model capable to represent unequivocally a decision-making unit, that is a subject who interprets, rationalizes the firm context and qualifies adequate organizational schemes, capable to manage emerging complexity and to govern uncertain situations. Thus, it is reasonable to interpret the viable system model, that moves from the systems theory development.

\section{The Firm as a Viable System}

The viable system logic is widely considered a reference point for all the entrepreneurial organizations. Such relevance springs from considerations towards the firm openness, its adaptability and refinement of 'life-supporting' logical operations. In the end, the necessity of governance unit selection has been emphasized as far as its choices and decisions qualify the firms evolution dynamics.

\subsection{Viable System Concept}

The viable system concept is not new. It has been introduced by Stafford Beer, one of the most relevant operations research theorist, known to have applied successfully cybernetics to management. A heuristic potential of his works, however, do not seem explicated enough ${ }^{6}$. Necessary to say, the viable system results coherent with an observational perspective of firms top-management presented in the following paper. Moreover, the viable system is particularly suitable for the firm system qualification.

The viable organizations have to struggle for existence, a statement particularly valid, if we consider changes (adjustments, transformations, reorganizations) of logic and physical assets (logic and physical structure) as also specific configurations developed in time. The prerogative of structure viability manifests itself in a systemic dynamism, in particular, in relationships established between internal and external (belonging to physical structures of other systems) components. In other terms, such viability is expressed by interactions between the firm and the context, turned towards learning, adaptation, development as also 
efficiency optimization ${ }^{7}$. As a consequence, a viable system can be defined as follows: it is a system that survives, remains united and entire; it is omeostatically equilibrated internally and externally; it contains mechanisms and opportunities to grow, learn, develop and adapt becoming more efficient in a proper context ${ }^{8}$.

In order to analyze and clear key-concepts of the viable system, it is necessary to underline the difference between a 'living system' and 'viable system'. The living systems, that is - biological systems (like human body system), are characterized by a number of properties and functions; they actuate specific physical and chemical reactions that can't qualify entrepreneurial organizations that represent a specific system composed of individuals and technical elements. The viable system, as emphasized previously, qualifies continuous interactions and relationships with the context, in order to assure the firms survival and its development. In fact, it is impossible to reproduce the components and to perpetrate 'species' through processes that have purely biologic nature.

\subsection{Viable System Properties}

In the light of the following considerations, the vital systems are open systems that are capable to survive only if contextualized on a proper field. Moreover, the viable systems are 'isotropic', in reference to their fundamental characteristics. In other words, they manifest a unique sensible imagine that goes beyond diverse appearances due to different point of views. According to an 'isotropic property, the viable systems can manifest themselves differently in relation to different physical structures, in a strict coherence the a proper identity. In reference to such identity, in fact, the viable systems can be represented by a unique category (Figure 1):

1. 'decision' area;

2. 'action' area.

\section{Figure 1: Viable Systems Identities}

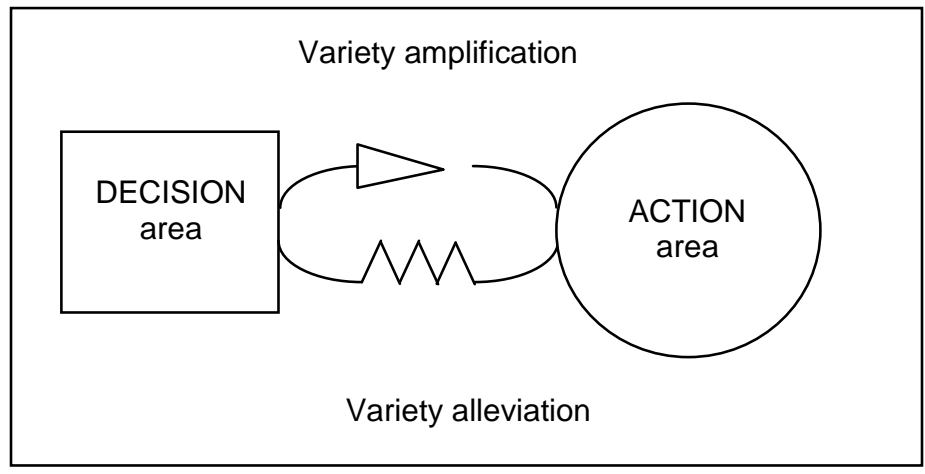


The connection between both: 'action' and 'decision' areas has sense only if related to the viable system's identity analysis; to be more precise, both areas could never be autonomous or independent. From the following consideration descends an interactive character of two distinguished areas; in other terms, area represented by a 'circle' or by a 'square' couldn't qualify the viable system, if treated separately and independently'.

The symbols dividing both areas (amplifying diode and resistance), represent the necessity to adapt available know-how and to allow an adequate information flow between 'action' and 'decision' areas. Just think about a presence of tacit knowledge, meant as 'know how to do', inherent in relational aspects of 'decision' area. In particular, the difficulty of connecting both areas descends from the firm system regulation, globally intended across an optimal know-how combination.

Moreover, it is necessary to consider the way that activity performed by the viable system $X$ on the $L$ level are conditioned by the necessity of satisfying $L+1$ supra-system requirements. In the same manner, sub-systems of $X$ system on the L-1 level, qualify their activities generating results coherent to their needs, rules and components of the $\mathrm{X}$ system itself. As a consequence, it is possible to observe that:

- goals and objectives, that allow the $X$ system to emerge from the expanded structure, derive from a single supra-system or a number of supra-systems that influence directly the X system;

- it is not relevant to analyze characteristics of a certain X organization separately; in other terms, a kind of 'holistic approach' is required in order to contemplate the existence of supra-system that includes $\mathrm{X}$ and of sub-systems included in $\mathrm{X}^{10}$.

Thus, from the following conclusions descends a conviction of the impossibility of observing the system in virtue of social organizations study. In fact, the only way to understand systems dynamism and its characteristics moves from the subsystems (L-1 systemic level) and supra-system ( $\mathrm{L}+1$ systemic level) analysis.

\subsection{The Firm as a Viable System}

The viable system concept, despite being an element of an interpretative clarification, does not satisfy fully the need of firms representation in a systemic key. First of all, the difficulty of operative dynamism schematization in reference to the 'action area' seems evident. At the same time, the 'decision area' (conscious of a general character of decisions) appears unrepresentative when it comes to the decision-making processes controlled by the top-management. Naturally, it doesn't compromise the viable system adequacy and interpretative utility, even if its explicatory force has been undoubtedly reduced. Such explicative impairment and inadequacy to represent the present firms reality is ascribable to the evolution not only of the firm itself, but also of the entire context.

After the Second Great War, many significant changes in the firms context have occurred. In fact, such changes have influenced significantly the operative and decisive dynamics, as also have contributed to the external context complexity. Such complexity was expressed by 'supra-systems' and requirements transformation as also by changing rules imposed to the firm system. As a result, 
hierarchical specialization has been significantly reduced, entailing a consequent operational rigidity decrement and a consequent flexibility recovery. It has conferred a major 'freedom of movement' to single macro-components, allowing them to accumulate competencies and abilities to design their own routines. Such evolution lines seem connected to a progressive acknowledgement of human resources role, that couldn't have been reduced to a simple machines workability. An substantial evolution of the way the firm operates and behaves, made the Figure 1 not exhaustive enough.

In the light of these considerations, it rises the necessity of a further interpretative effort in order to qualify the firm as a viable system, able to reassume all the fundamental principles expressed and summarized by viable systems aligned with a paradigmatic tradition of management studies.

It is necessary to understand how is it possible to reach the 'firm as a viable system' notion through its isomorphic representation respect to the viable system definition. Moving from the Figure 1, it is necessary to identify typologies of adaptations aligned with firms evolution path, that aim for a more coherent viable system representation. In particular:

1. it traces a link with typical managerial concepts;

2. it allows to formalize the firms perspective as a governmental body (which aims to activate and to orientate the system towards a proper objectives and goals fulfillment by accomplishing sophisticated operations supported by a corporate know-how and autonomy respect to 'routine' decisions);

3. it emphasizes the open-system concept, able to survive in synch with the context evolution by adjusting a proper organizational scheme in a dynamic manner and by continuous resources exchanging with third systems.

It is needless to clarify the first point, retained easily deducible from the purpose of the following study. The second point, on the other hand, calls for an ultimate consideration. In fact, it is retained necessary to assume an adequate point of view in order to inquire into different firms behaviors. Thus, it is essential to consider and to explicit the existence of two 'dichotomous' fundamental moments in the entrepreneurial activity, that is: the government and the management. It's representation as a viable system, if valid, has to reflect such dichotomy, that qualifies a perspective of a governing subject, that observes, elaborates, plans and implement, making use of a reactive operative structure. From the following observation descends the third point, that emphasizes the necessity to evidence decisions meant to guarantee a flexible organizational scheme, perfectly functional to the firms objectives.

As emphasized previously, the system can be retained viable only if able to survive by activating learning processes. Thus, in general, the viable system allows a firm to adapt to the context or even to modify it, whilst the conditions are conducive. However, we haven't mentioned yet how does the viable system achieve it. In fact, it is necessary to specify the way that different decisions are made and, finally, how are they being transformed into real tasks to accomplish. Afterwards, it is necessary to understand which variables move governing subject decisions (to adequate, to transform or to reorganize) towards objective achievement. 
A goal of the following hypothesis, then is to show how does the organizational scheme link to the external context. More precisely, it's about a role of the corporate governance subjects in complementing traditional 'routine decisions' with a corporate know-how development. Thus, the firms organization has to reflect the external context, that goes from the market structure to the viable suprasystem. The firms government, on the other hand, is called to exploit its capabilities and skills in order to elicit all the opportunities deriving from the external context. Afterwards, from all the decisions contained in the 'decision area' of the viable system, we decide to extrapolate those regarding the governmental activities. In other terms, we want to separate 'governmental subjects' decisions from the managerial decisions (Figure 2). In fact, managerial decisions are deeply rooted in action, matured with time, indivisible with an internal context and, for that reason, directly referable to technical abilities contained in the 'operation' area.

Figure 2: The Extrapolation of the Governance 'Decision' Area from the Whole 'Decision' Area.

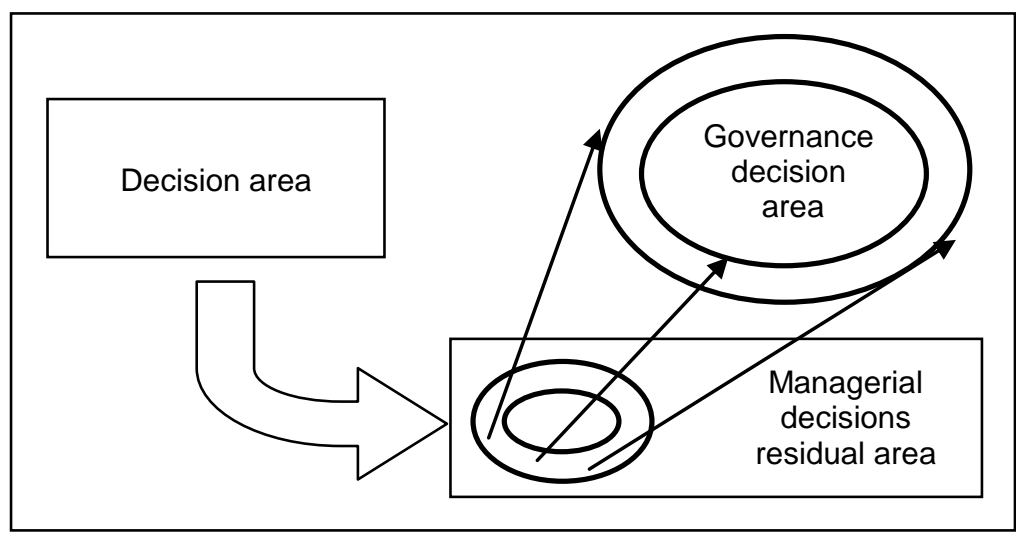

Let's assume that remaining tactical / operative decisions can be added to the 'operation' area. As a result, a new aggregate containing not only out-and-out operations, but also tactical / operative decisions, forms a corporate operative structure coinciding with a 'managerial area'.

At this time, it is interesting to recall the expanded structure notion and, subsequently, to focus on the operative structure concept. If possible, the relations between internal and some external components are qualified exactly in the expanded structure area. Nothing has been said, however, about intrinsic capabilities of related components and neither about the quality of such relations. The representation of the expanded structure, however, doesn't illustrate its historical evolution. In fact, it doesn't explain the passage from the 'early' expanded structure, through corporate governance reorganization and autoorganizational internal processes, towards the structure observed afterwards. Such competences and skills, possessed by single components, are implicitly present in the operative structure. Thus, it is possible to talk about some kind of 'rule of change' qualified by the operative structure potential (know-how and routine operations) and its limits. As a result, both: expanded and operative structures are 
subjected to 'the rule of change' (continuous systemic redefinitions wanted by the corporate governance subjects).

Thus, the representation summarizes all the conceptual elaborations that form axiomatic basis of our modeling process. Although it preserves characters related to the viable system identity, the new representation seems perfectly adequate to the corporate system description.

Figure 3: The Firm as a Viable System Extracted from the Viable System Model

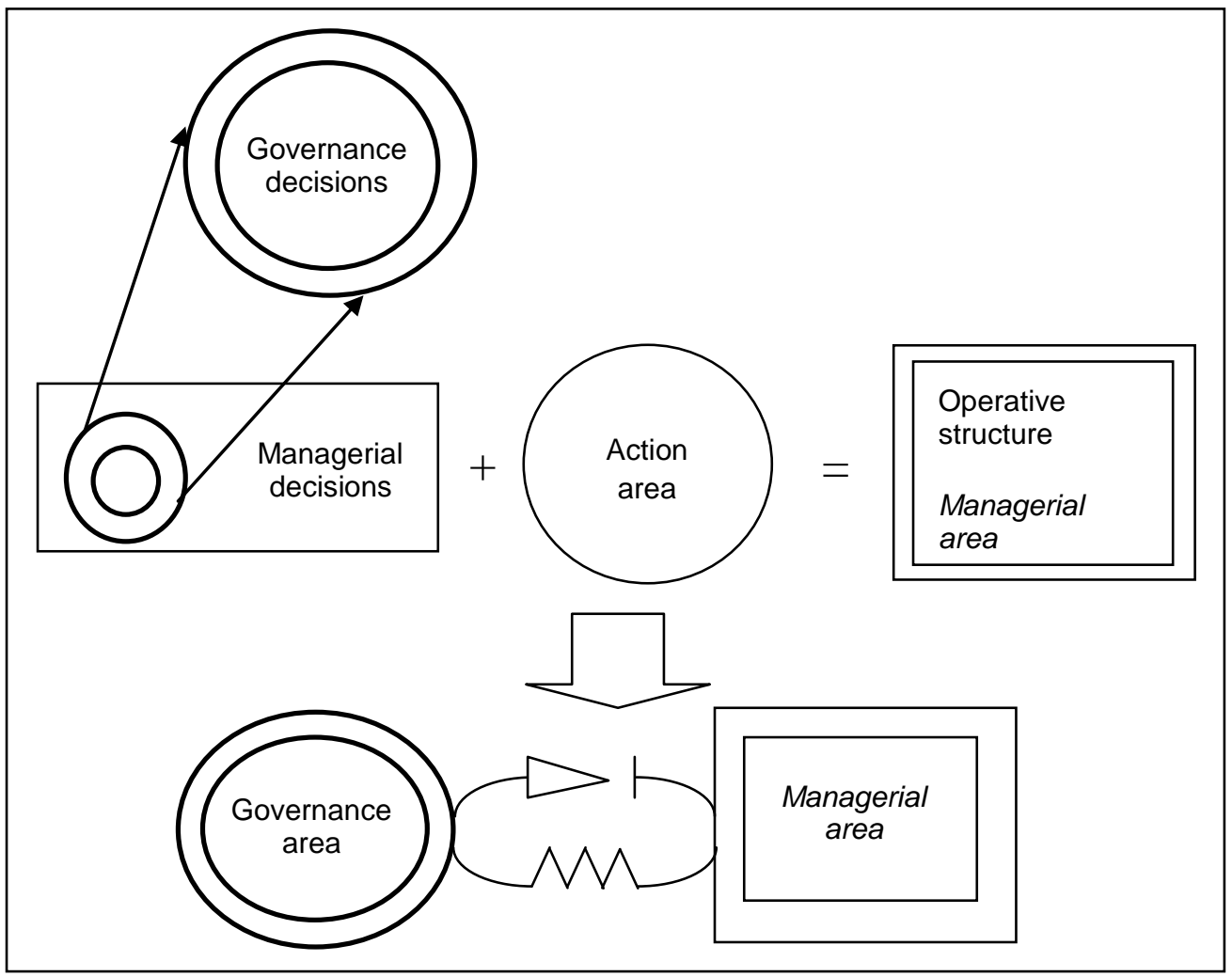

\subsection{Firm's Viable Systems Overview}

Once the new representation has been qualified, it is plausible to go over the viable system properties. We can't forget, however, that the components of the initial 'decision' and 'action' areas has been previously transposed. After having verified the properties pertinence, it becomes possible to extend conclusions and remarks referable to the 'viable system' concept over the 'firm as a viable system' theory. As a consequence, it becomes evident that the new conceptual elaboration contributes to an immediate comprehension of the viable system postulates.

The first property that qualifies the viable system and, in particular, its ability to survive in a particular context, seem confirmed by consideration of the firm as an open system integrated with the environment. Naturally, it's about a continuous interaction and resources exchange between both: the firm and the external context in order to strengthen the firm's ability to survive. In fact, a correct 'decryption' of the context represents a crucial point in the firm's governing activities as far it 
emphasizes the importance of operations necessarily coherent with quailquantitative composition as also with different systems powers in a specific context. Thus, the firm's 'viability grade' (firm's ability to survive in different contexts) depends on an efficient research, a careful decryption and a correct interpretation of supra-systems. As a consequence, the firm is not describable 'a priori' but necessitates to be reported to its ability to give life to objectives and expectations, that are ultimately extended by proper supra-systems. The corporate governance is called to regulate the grade of openness by giving flexible answers to the context dynamism.

Although the second property - the isotropy, coincides with remarks described previously, it is retained plausible to make some interesting considerations. Thus, it is necessary to underline the qualifying role of the isotropy (the viable systems identity) in reference to an adequate research methodology implementation. Moreover, such consideration is useful for a correct comprehension of intersystemic relationships.

Our definition of conceptual frames, which would be common for all the companies and would define the viable system identity, recalls two general categories (firm's government body and the operative structure) as also identifies all the structural aspects (detecting and analyzing the components and the relations) and diverse systemic objectives (for instance, projecting evolutionary steps). In fact, all the firms (industrial, commercial or even service firms) have the same identity, in other terms, they share the same organizational scheme: the presence of the government body and the operative structure. It is plausible to underline that the following aspect was absent in the previous representation, that in order to qualify concepts like 'dynamic capacities' or 'firm specific', would amalgamate both: 'decision' and 'action' areas with a following interpretative mystification.

The third property claims that objective accomplishment is significantly affected by dynamics and dialectical report between corporate governance and relevant supra-systems. The viability, on the other hand, is shaped by a capability to satisfy diverse supra-systems objectives as also to trace a link between different subsystems interests. In the light of the following statement, it becomes clear that the category of supra-systems and sub-systems necessities a subject that would supervise an effective objectives fulfillment. In fact, the corporate governance role in analyzing and monitoring continuously the sub-systems expectations and motivations, but also in detecting supra-systems goals and objectives, is crucial and, for that reason, requires an ultimate enlightenment. As a matter of fact, the government body is called to design an appropriate and profitable 'structural coupling' necessary to share objectives, considering all the resources and skills codified in the firm's operative structure.

Thus, it is possible to notice that the entrepreneurial idea validity is linked to the corporate system's ability to survive in a determinate context. The environmental context, as a synthesis of supra-systems which the firm interacts with, is nothing but a result of an interpretative effort made by the firms government body in reference to the external context.

If we analyze the viable system properties in the 'firm as a viable system' key, we will be able to recognize two fundamental aspects:

1. the 'firm as a viable system' category is included in the wider one - 'the viable system'. It reveals more clear once the relative postulates are recognized and their validity is confirmed; 
2. a passage from the first to the second representation traces an itinerary which brings to characterize structural and systemic aspects of the firm as a viable system by following two vectors: the formalization and the contextualization.

\section{The Relation Between the Firm-System and the Environment}

Recognizing a viable system potential in a firm is relevant not only for a better internal dynamics comprehension but also for a greater qualification of reports between the corporate system and surrounding entities (systemic or not). In fact, the viability poses on the awareness towards the context variability and, consequently, on the ability to take crucial decisions for the firm's survival. In particular, the governance and the management decisions are centered on detecting, managing and optimizing conditions necessary for this objective. As a consequence, the following logic outlines a governance fundamental role in recognizing, describing and, finally, in interpreting objectives and expectations manifested by the external entities. Moreover, it delineates and implements different solutions for the systems development, maintaining a needed coherence with the context.

Thus, the objectives accomplishment is deeply rooted in the governance ability to implement a rational context's description and interpretation process. Consequently, the firm creates a sort of a map of entities which qualifies the context and, subsequently, determines possible behavioral dynamics.

\subsection{Some Useful Conceptual Categories in Order to Represent the Firm's Environment.}

a) The relevance and the influence

The firm as a viable system, through the governance organization, identifies other entities operating in the context. In fact, the identification and the classification of the entities represent a fundamental aspect for a further viable system development and determination of variables necessary for survival.

Thus, the entities that 'populate' the viable system are differentiated first of all according to their relevance. In particular, with such entities the corporate system establishes relations and interactions (differing among each other with a grade and with a nature), determining conditions that can be resonant or consonant.

The relevance of third entities can be qualified through two attributes:

1. the 'influence' practiced by the entity;

2. the 'importance' of the resource given to the corporate system.

It allows to make the first distinction between 'relevant systems' (subsequently called 'supra-systems'), that is a distinction between influential systems that possesses one of the critical resources from the systems that, despite being influential, do not possess exclusively any resource. 
Another important distinction refers 'limits' and 'rules' notions. In other words, the following distinction permits to differentiate possible impacts of diverse entities on the firm as a viable system.

The 'limit' has a general valence and obligatory nature. In reference to the firm, the limits serve for public bodies to determine technical requirements in order to protect the public interest ('regulation'). For instance, in the manufacturing process a 'limit' represents a number of technical specifications that machines have to respect (necessary technical characteristics to benefit from the electricity supply on the industrial level). In reference to the financial system, on the other hand, the limit can be represented by specific conditions imposed to the corporate system (requirements necessary to enter the stock market).

It is evident that external entities are structurally connected with the firm as a viable system. Moreover, they impose limits that have to be respected in order to define relevant conditions of consonance with these entities.

The 'rule' notion, on the other hand, derives from the governance ambition to trace a link between the corporate system and a particular entity. In fact, 'the rule' seems to be a kind of systemic conditioning, connected to firm's workability and to objective accomplishment. In substance, the corporate system dynamics is influenced not only by the regulation activities of the most important entities, but also by the 'self-regulation' activities sketched out by the corporate governance. Thus, many firms decide to embrace behavioral rules by endorsing standards that facilitate consonant reports with entities. For instance, many industries impose rules in order to make their products compatible, even if offered by different producers. The unification process is particularly relevant in context of a progressive market integration as far as it allows companies from different countries to adopt the same component of a complex product. In other terms, the companies can refer to the same manufacturer with a remarkable market power (specialized manufacturing process with a noteworthy potential to generate economies of scale).

Logically, the self-regulation activities don't regard only the technical aspect. In particular, the self-regulation operations manifest themselves through the behavioral standards referable to the same governance body (just think about the administrator's behavioral code), to the employees or to other entities operating in the same context (trade, suppliers, market).

$\square$ In reference to the Italian law, the self-regulation is expressed by a self-discipline code emanated in 1999, which refers to all the firms listed on the Stock Exchange. The objective of the following code is to generate consonance between the firm and the international investors community. Moreover, it qualifies an organizational model and, consequently, delineates a repartition between responsibilities and powers, with a correct balance between management and control.

The self-discipline code was drafted by a special committee coordinated by the Italian Stock Exchange President and composed by the firms representatives, institutional investors, issuing and investors. The objective of this code is to enable the companies to operate freely in the capital markets and to propose an organizational model adequate to govern the risks and possible conflicts of interest. 


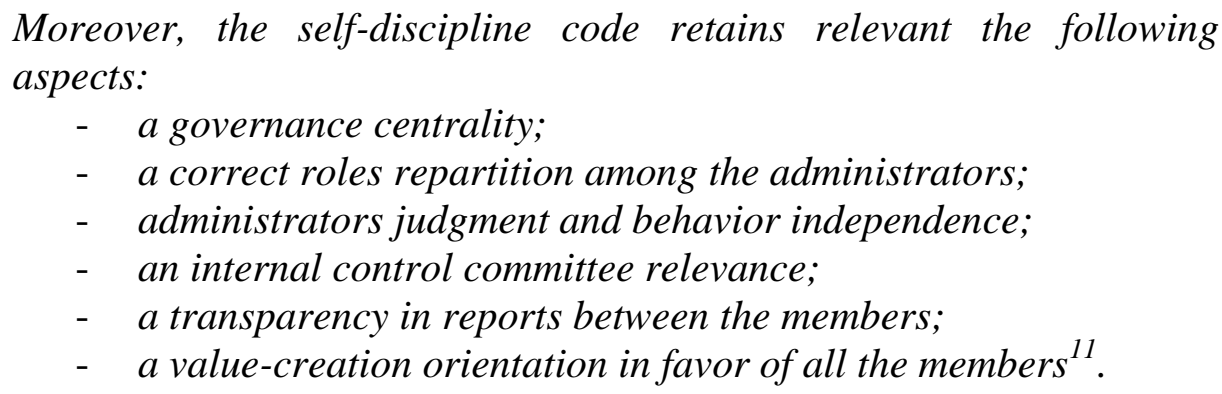

It becomes clear that the following rules are important for the firm's evolution dynamics in 'consonant' conditions and, on the other hand, they represent a relevant prerequisite to reach resonant conditions with other influential entities.

In the systemic perspective the limits determine characteristics of the report between two entities, that is, they represent a limitation of a single behavioral area. The rules, on the other hand, identify the will of two or more systemic entities to pursue collaborative behaviors and to establish an order that would be commonly respected. Moreover, it is possible to notice that the limit follows first of all the relation and, secondly, the structure. The rule, one the other hand, regards the processes, characterized by different dynamics level where the actions and its results are evident.

b) The ability and the level of openness

The possibility to interact with the external entities is connected to the level of the firm as a viable system openness to relations with the external context. Thus, it is necessary to distinguish the possibility of openness (meant as a potential ability to connect with the external context) from the governance will to take advantage of these potentials.

Thus, the 'openness ability' is nothing but a system's potential to interact with the external context by exploiting firm's structural resources. To be more precise, it is necessary to underline that the first definition of such resources occurs when the organizational scheme is defined. In fact, in the following phase the firm declares its resources retained relevant in perspective of the systems openness. Secondly, in terms of realizable relationships, the organizational schemes defines modalities to realize the openness.

The level of openness, on the other hand, refers to a governance volitive activity to modulate the use of the openness ability embedded in the structure. The governance determines the relations and interactions with external entities in order to generate consonant and resonant behaviors with the context.

$\square$ Just think about a company that exports local products. It is logical that, on the organizational scheme level, such company requires an openness towards particular foreign markets. Once the physical structure is defined, it is necessary to specify the organizational scheme. In our case, a firm can collaborate with foreign suppliers, foreign representative agencies or a proper distributive structure. 
The corporate governance, in the moment of organizational scheme delineation, has a certain level of openness, able to adapt to a variety of objectives through precise modalities of use. The governance decision-making autonomy allows to decide how and how intense is its level of openness.

c) The consonance and the resonance

Also these conceptual categories are structurally connected to the dichotomy between the structure and the system. The consonance concept, for instance, is strictly connected to relation and interaction notions. Moreover, it can be meant as a sort of compatibility between the systems that enables, at the same time, their mutual interaction. Just think about an orchestra, having a lot of instruments is necessary but not enough to play the right music; the instruments have to interact and be consonant, in other terms, their sound put together have to give life to the music composition. It is logical then, that the compatibility impose on the instruments to 'sacrifice' their sonority potential in order to obtain the best possible result.

It's obvious that if you want to make it work, three instruments must 'sound' with a determinate resonance, preferably inside a dotted-line area (Figure 3). It is possible, however, that the instrument can play solo, detached temporarily from the whole instrumental ensemble.

The following conceptual simplification facilitates better comprehension of activities conducted by firms integrated vertically or horizontally. In fact, the firms which decide to develop conjoined activities need to look for a consonance. Exactly like musical instruments, the integrated firms must tare proper manufacturing, logistic and administrative processes structuring in a manner that enables the consonance range determination.

$\square$ A report between American agriculture and industry is a perfect example of a consonance and resonance research. All the producers are unified through an association (for instance, peaches cultivators in California are united across the 'Producers Canning Cling Advisory Board') that together with canning industrialists (California Canning Association) coordinate both industries, updating periodically a 'marketing order' related to the products (in our case, the peaches).

A 'marketing order' then, is a number of obligatory rules for cultivators as also for the producers of the final product. Moreover, such rules can be solicited by both: farmers and industrialists even if in most of the cases the initiative is conjoint. The project is secondly discussed by the farmers and producers with the top management. Finally, once an agreement is reached, both: farmers and producers are invited to vote to approve the final version. Such version, called 'marketing order' is nothing but an obligatory rule.

A 'marketing rule' is applied by the Board, constituted by the farmers representatives, vendors and public powers. 
A 'marketing rule' qualifies also the Board powers, in most of the cases, it's about a control over the production volumes, the quality or technical and economical research projects.

The resonance, on the other hand, refers to a perfect consonance development. Thus, it's about a sharing process accompanied by a sense of belonging and harmony, as also about a progressive structural borders assuaging generated by the maximum level of openness. In front of such situation, a mutual confidence and perspective shared between the systems have contributed the new inclusive reality solidification.

The consonance and, most of all, the resonance with a relevant supra-system allows the firm as a viable system to detect adequate conditions in front of all the entities belonging to such supra-system. In other words, if an industrial company pursues and attains the resonance with the financial supra-system, it generates consequently also the consonant conditions with single banking sub-systems. In fact, having generated the consonance and, if possible, also the resonance with a particular supra-system, means having adjusted a proper structure and behaviors to diverse requirements, motivations, expectations and sub-system's objectives. Moreover, it means to reflect the financial sub-system requirements expressed by the components assigned to relate with the external context (in this case - the banks).

$\square$ In reference to reports between the firms, the consonance and/or resonance generation is evidenced by a major or minor partners involvement in mutual projects. In particular, Sun-Microsystem- a market leader in microchips, smart cards, systems, programming languages, has imposed a relational approach based on the selection of few suppliers, particularly dynamic and innovative, with whom the firm has developed partnership reports.

The relations activated by Sun-Microsystem are distributed on a number of levels, in relation to the level of involvement required by every partner.

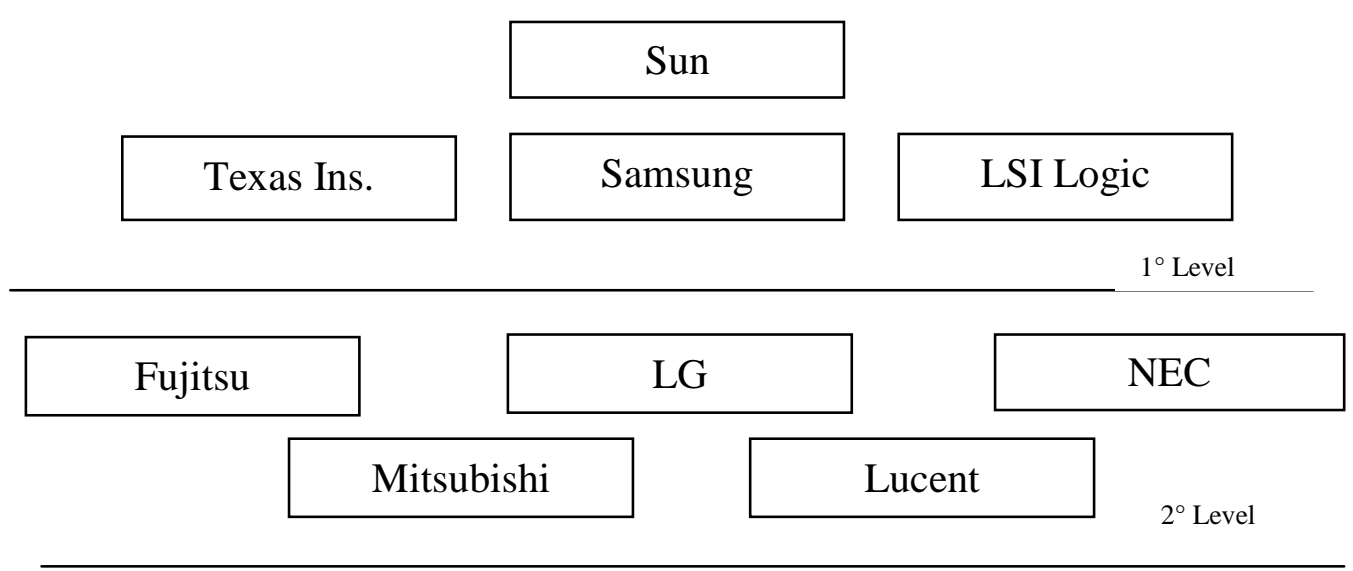

Source: A. Lanza, Knowledge Governance, Egea, 2000, p.140

On the first level, are positioned all the suppliers with whom Sun has activated reports that we could retained as resonant. With these 
partners, Sun delineates a technologic development (co-branding, codesing etc.) and market development prospective (new markets, new competitors, new products, etc.). The interactions are very frequent and involve permanent 'inter-firms' working groups. In such groups, the Sun managers meet every six weeks their partners in order to discuss principal evolution tendencies. Generally, Sun is likely to know its partners opinions about different solutions applicability and practicality. In fact, such information serve to start a co-planning process guided by a common standard, present in all the stages. On the second level, on the other hand, we can pinpoint suppliers with whom Sun has consonant reports. Essentially, it is about relationships based on a specific standard implementation by a Sun's supplier. In this case, the interactions present purly operative characteristics.

The activated relations articulations then, depends on the relevance of the component in generating a competitive advantage. In fact, on the first level are present critical components suppliers (the memories and microprocessors) and on the second level, all the companies that supply important, but not critical for the competitive advantage, components ${ }^{12}$.

\subsection{The Context as a Systemic Network}

The external contest has been always meant as an indistinct set of entities. From the corporate governance perspective, such entities can be qualified as systems which receive a resources input generated secondarily to the output of goods and services. In reference to the external context analysis, it becomes difficult to identify the existing systemic entities and to recognize their power of influence the firm as a viable system evolution trajectory. The following perspective requests, however, an ultimate consideration.

Firstly, the corporate governance is called to decide the base for differentiation in order to distinguish diverse aspects of the entities. Such differential aspect is indicated in reference to proper viable system characteristics. In essence, we refer to the existence of an operative structure, provided with self-organization skills and a remarkable level of entrepreneurship, as also to the role of the corporate governance in influencing the systemic entity dynamics. In reference to the following statement, the external viable systems can assume different aspects:

- 'the embryonic systems'; they may be ascribed to the 'markets' notion;

- 'the systems in the works'; such category is related to the 'multiple entities', in other words, the entities composed by two or more entities (just think about the districts, industrial poles or about networks); the identity assignment requires, however, an evolved corporate governance skillful enough to drive the sub-systems choices;

- 'the viable systems'; such category has all these characteristics and answers to all the postulates and rules that differentiate the category of systems described above.

It is possible to position on the evolution line all these systemic configurations, moving from the embryonic system, through the systems in the works, towards the viable systems. It is clear then, that such evolution regards also the corporate 
governance role, its influence, the ability to dictate the rules, limits, expectations and objectives of the viable system.

For instance, we can refer to a different level of trade realization that a governance of a company may cope with (just think about differences between Italian and French distribution systems). The difference reveals evident and obvious during the 'planning' step, when the company plans to position proper products in the French trade. In this case, super group purchasing organizations are qualified as an insurmountable filter for a supply access. As a result, it is necessary to perceive the limits and the rules respect, a widespread and efficient information system and, above all, the trade's impact on the companies policies and its conducts. The Italian trade on the other hand, doesn't present the same force and isn't so influential, at least till now.

Thus, the corporate governance can be presented as a differentiated systemic entities network characterized by a continuous dynamics. In fact, the embryonic systems are nothing but a set of viable systems potential that can progressively emerge in relation to spontaneous processes or to organizational supremacy conditions generation.

The classification, then, is valid and directly referable to the statement according to which the correct analysis and environment's interpretation permits to minimize the risk related to the lack of synchronization between the entrepreneurial operations and rules or limits deriving from the context.

\subsection{From Taxonomy to the Context Dynamics}

The approach we decide to follow in virtue of inter-systemic relations analysis is based on the following assumptions:

1. the governance of the firm as a viable system is an observer who investigates a context;

2. from the observer's perspective, the context seems 'sprinkled' with entities, possible classified as follows:

- the embryonic systems;

- the systems in the works;

- the viable systems.

3. there are different systems that interact with the firm. Such interaction realize an inter-systemic report, possibly 'reread' in the relevance perspective, in other words, considering the pressure mutually exerted by the interacting systems.

Thus, it is plausible to underline that, from the corporate governance point of view, the entities present in a particular context are perceived differently in time. Naturally, it is due to different industrial organization conditions that emerge directly from the context. Consequently, such structural variability gives a new light on the context dynamics comprehension.

For instance, we can think about a firm that interacts with its supplier. The corporate governance is aware of a possible 'linkage' between the firm and various suppliers inclusive entity; a 'summarizing' entity that gathers the companies with 
similar characteristics. Thus, the corporate governance perceives the existence of the market meant as a non-viable supra-system's 'structure', logically free of any kind of dominant power able to affect behaviors of single suppliers. On the other hand, however, such market is potentially an embryonic system. In fact, gradually on the market appear firms influential enough to condition other companies. Such influence could derive from bargaining power conditions related to:

- purchasing volumes;

- particular economical and financial characteristics that are retained strong points;

- orders stability and guarantee of perpetuity;

- special characteristics of the resources;

A process that highlights the influences and dependences, brings to define a scheme of reports that make the systems emerge. It becomes possible, then, to formulate (temporal or steady in time) networks that embody an attempt to give life to flexible industrial organizations, established on specialized tasks and outsourcing. That's how the new systemic form profiles, that is - 'the system in the work'.

It is interesting to notice that the perception of such entity development is linked to the possibility of reviving the corporate governance well defined and lasting in time.

It is necessary to distinguish two possible 'evolutionary paths' of 'systems in the work':

\section{- 'bottom-up';}

- 'top-down'.

Both, not necessarily can be retained alternative; in fact, in some cases they can integrate and strengthen each other.

The hypothesis of 'bottom-up' networks formulation is corresponding to the one described previously. In perspective of a progressive reports delineating, the markets witness a network emergence. It is not assured, however, that such aggregates will share one, stable and steady reference point - that is a defined corporate governance responsible for the operative structure activities supervising. Especially in the hi-tech contexts, characterized by a continuous innovation and a rapid obsolescence of goods and processes, the networks (originally 'bottom-up') can express atypical corporate governance models due to the limits of time and the technological leadership concept.

In some situations, however, other subjects of the network aspire to enforce their leadership; in these cases the network's corporate governance changes. In other words, the corporate governance alternate continuously and dynamically in time (that is, in different phases of network's life). Moreover, such logic rewards a plurality of possible technological contributions in evolutional perspective of development.

The 'top-down' approach, on the other hand, presupposes the domination of one corporate governance, stable and lasting in time. It's about firm's 'sponsor technology' role, it's ability to impose technical standards on other subjects interesting in taking part of the network as suppliers. 
Another step is represented by the evolution towards the viable system. The corporate governance qualify strengthen itself, making the operative structure entirely resonant and the identity integrated. Its previous dependence reports are redesigned (in favor of the firm itself) in order to optimize the firm's influence and strengthen its position on the market.

An ultimate evolutional hypothesis refers to direct effects on the market. Such delicate phase, a passage from the 'system in the works' to the 'viable system', is connected to multiple factors:

- the permanence of the conditions of consonance and, if possible, of the resonance between diverse sub-systems (firm as a viable system);

- the 'top-down' approach;

- the consonance with the context;

- the relevant systems will, positive or negative, to promote the development.

In the firm's reality - or more generally in the economic context, it is possible to face different examples that bring to evolutional paths, from the 'system in the works' to the viable system, and innovative - from the 'system in the works' to a 'break-up' in independent companies.

$\square$ Example of the systemic evolution: Italian Distribution System

The Italian distribution system can be interpreted in different ways in the matter of governance and, consequently, of a particular firm that analyses and observes.

The governance of a small industrial company (involved in consumers good production), has changed significantly in the last 40 years. In fact we can identify the following phases $(*)$ :

1)'50-'60 - an extensive phase (embryonic system)

- A fragmented distribution that lacks any kind of coordination.

- Heterogenic intermediaries

2)'70 - a reorganization phase (the system's accomplishment)

- A progressive harmonization of intermediaries typologies

- First horizontal integration processes

3)'80 - a service industry evolution (the system's accomplishment)

- Big-surface shops development at the expense of small retailers

- Associations and distributions centres

4)'90 - integration phase (viable system 'prelude')

- Vertical and horizontal alliances, in some cases- on international scale

- Production and distribution chain reorganization

- Inter-organizational advantages exploitation due to new technologies

(*) The first three phases have been described by Fornari D. in 'Trade marketing strategies', Egea, 1990, p. 29-50 
$\square$ An example of a system's regression: IT technologies suppliers for Italian small and medium businesses

IT technologies suppliers, from the small and medium-sized businesses governance point of view may by described as follows:

1) '80 - embryonic system

- Supply market extremely fragmented, characterized by different small software producers, able to personalize their offering to different consumers needs

- Low solutions and programming languages standardization

2) '90-system's accomplishment

- Operative applications standardization

- Presence of multi-base software-house (also foreign)

- Progressive intermediates concentration

3) After' '98-embryonic system

- Technological evolution of programming languages

- Tools and IT competencies extension

- 'in home' personalization

- Domestic software-house revitalization

It is necessary to notice that in 'top-down' model it is easier for the firm to keep the position in time, as far as the development objectives descends directly from the firm's planning activities. Moreover, it becomes easier to estimate the risk of relevant systems intervention or other influential entities that, for their own interest, could obstruct the systemic development. In the 'bottom-up' systems, on the other hand, can be conditioned by the relevant systems in virtue of a greater competitiveness. In the communication industry, for instance, the State can intervene on network's activities.

\subsection{Towards a Greater Systemic Relevance Specification}

The external systems analysis (external respect to the firm as a viable system) is made according to a fundamental base for differentiation: the relevance. The relevance is meant as an external system's ability to influence the firm as a viable system's survival. The corporate governance role, then, is to understand the importance of diverse systems present in the context and, if necessary, to decide the priorities.

In order to analyze the relevance of different systemic entities present in the context, it is necessary to identify and to describe single resources; secondly, it is possible to delineate a functional scheme of relations between various resources. As a result, it becomes possible to 'sketch' a map of firm resources and to detect all the systems that derive from these resources.

A consecutive analysis identifies specific characters that could qualify features like the resources importance and the systems influence. In detail, specific features can be:

a) in order to the resource importance:

- a number of possible alternatives to purchase a particular resource;

- an average unit cost related to the resource purchase; 
- a report between the volume of purchased certain-type resources and the volume; of all the resources in the same period;

- probable losses in front of 'out-of-stock';

- the importance of processes that involve a particular resource;

b) in order to systemic entities influence, specific characters could be:

- a bargaining power, representing all the limits, more or less incident, with regard to both: the survival conditions description and the firm's performance;

- the ability to set the rules;

- the quality and the quantity of sanctions in answer to a missing rules and limits observation;

- as in case of any complex phenomenon, the corporate governance is called to delineate significant characters and, consequently, to recognize their importance in relation to possible aspects of the phenomenon. The composition of entities present in context, defined in reference to its importance in a particular resource supply. It allows the corporate governance to:

- qualify a single systemic entity and the whole context in particular reference to the opportunities and threats for the corporate system;

- set an importance scale of diverse systemic entities and, secondly, to decide the priorities and the relational quality;

- orient the evolutional dynamics of the firm in consonant and resonant systemic conditions.

$\square$ Study case: a small industry business operating in consumers goods market as a plastic products producer.

Characteristics:

Small producer of disposable plastic products for groceries

Governance characteristics:

Expressed property; the second generation of family business entrepreneurs. Responsible for the family business's reorganization, passing from a traditional business to a small industrial company.

Critical resources:

Financial

Human

Technological

Production (raw materials)

Market

Social conditions (safety, education)

Possible governance considerations:

The technology, even if specific and diffused, is not critical. Its influence is determined by the maintenance necessities respect to the efficiency imperative.

The human resources are widely available 
The product typology imposes a report with distribution intermediaries with a remarkable bargaining power and being a member of trade organizations.

The supply market operators are not likely to share the same rules when it comes to the raw material supply.

The financial resource is surely critical; outbound flows are poorly standardized (just think about a necessity of purchasing a stock of raw materials in favorable market conditions) and inbound flows significantly deferred in time (the conditions imposed by the distribution make the payments defer on average to 60 days)

Possible considerations developed by the governance in reference to the relevance and the influence of diverse systems:

A technology supplier (as a part of the technology supply market) is retained an influential system.

The human resources market, on the other hand, is not considered an embryonic influential system.

The trade organizations are believed to be relevant systems.

The raw materials supply, as an embryonic system, is an influential system.

The financial system, as a viable system, is surely a relevant system.

\section{Conclusions. Towards an Inter-Systemic Model}

A decision-making process that leads towards the selection of systems and relationships retained relevant for the firm's survival, is characterized by at least four fundamental steps:

- identification and classification of the entities;

- estimation of the entities importance (relevance and influence);

- interpretation and limits weighting; the assessment of the effects on the performance deriving from respecting the rules;

- setting the objectives: the coherence of the objective refers to the firm's ability to respect the rules and limits, deduced from the third systems relevance comprehension.

The following process originates two fundamental phenomenon of Management: innovation and firm's crisis. Such phenomenon may seem distant or even complementary; an accurate analysis, however, reveals that they are nothing but a result of a correct interpretation (that may be positive or negative) and consequent transposition in objectives, limits and rules deriving from the relevant systems.

It is necessary to emphasize, that relevant systems do not only influence and solicit the corporate system. On the contrary, at the relevant system level, a numerous premium / sanction mechanisms are being activated in order to set the rules determining the firm as a viable system's relations with relevant system at Llevel.

The firm retained as a viable system at the L-level and depending on diverse supra-systems, acts like a sort of filter and composer in one, answering adequately to expectations and pressures from the supra-systems through a number of 'inter- 
systemic' objectives (designed to generate value for the relevant supra-systems). In order to set these objectives, the corporate governance is called to value the compatibility with firm's operative structure.

As a consequence, the corporate governance functions are:

- filtering / interpretation of the direct supra-systems influences;

- filtering / interpretation deriving from the indirect supra-systems;

- reconcilement / mediation between two types of influences;

- visualization at the L-1 level of the influences deriving from the L+1 level systems.

Through these actions, the corporate governance guides the system's evolutional dynamics; a dynamics inside the environmental context meant as a complex of numerous supra-systems levels. The corporate governance acts till the system's evolutional dynamics is not qualified by a little probability of survival. From this perspective, the model proposed tries to reconcile the probability of survival with the ability to satisfy the relevant supra-systems expectations. Naturally, it request an analysis of skills, abilities and expectations articulated on diverse sub-systems. At last, the ability to satisfy the relevant supra-systems expectations is being represented in the systemic pe perspective, the firm's ability to generate value.

\section{Bibliography}

Beer S., Diagnosing the system for organization, John Wiley, 1985.

Beer S., Brain of the Firm. The Managerial Cybernetics of Organization, The Penguin Press, 1972.

Borsa Italiana, Codice di autoregolamentazione, http:॥www.borsaitalia.it\9\122\218.html, 1999.

Brown L.R., Building a sustainable Society, Norton, 1981.

Cafferata R., Impresa, ambiente e innovazione. Come s'integrano la continuità e il mutamento nell'impresa, Giappichelli, 1995.

Capra F., The Web of Life, Doubleday - Anchor Book, 1996.

Ceccanti G., Lezioni di tecnica imprenditoriale, Cedam, 1996.

Ceccanti G., Note sulla struttura aziendale. Ricordi di un'ultima lezione, Ed. c.i.p., 1998.

Checkland P., Systems Thinking, Systems Practice, John Wiley, 1981.

Di Bernardo B., Rullani E., Il Management e le macchine. Teoria evolutiva dell'impresa, Il Mulino, 1990.

Emery F.E. (ed.), General System: Yearbook of the Society for the Advancement of General System Theory, 1956.

Epstein E.M., The Corporate Social Policy Process and the Process of Corporate Governance, in American Business Law Journal, vol. 25, 1987. http://dx.doi.org/10.1111/j.1744-1714.1987.tb00508.x

Fazzi R., Il governo d'impresa, Giuffré, 1984.

Fornari D., Le strategie di trade marketing, Egea, 1990.

Friedman R.E, Strategic Management. A Stakeholder Approach, Pitman, 1984.

Giudici E., Innovazione, impresa, ambiente, Giuffrè, 1988.

Golinelli G.M., L'approccio sistemico al governo dell'impresa. I - L'impresa sistema vitale, Cedam, 2000.

Golinelli G.M., Struttura e Governo dell'impresa, Cedam, 1994

Huant E., L'entreprise, unité cybernétique vivante, Edition de L'Entreprise Moderne, 1960. 
Johnson R.A., Kast F.E., Rosenzweig J.E., Théorie, conception et gestion des systèmes, Dunod, 1970.

Katz D., Kahn R.L., Le caratteristiche comuni dei sistemi aperti, in Emery F.E. (ed.) General System: Yearbook of the Society for the Advancement of General System Theory, 1956.

Lanza A., Knowledge Governance, EGEA, 2000.

Lovelock J., Gaia, Oxford University Press, 1979.

Maturana H., Varela F., El arbol del conocimiento, 1984.

Merlani C., Lineamenti dell'impresa industriale e dell'impresa mercantile, Cedam, 1966.

Morin E., Introduzione al pensiero complesso, Sperling \& Kupfer, 1993.

Panati G. Golinelli G.M., Tecnica economica industriale e commerciale, La Nuova Italia Scientifica, 1991.

Pfeffer J., Salancik G.R., The External Control of Organizations. A Resource Dependence Perspective, Harper \& Row, 1978.

Poincaré H., Les mèthodes nouvelles de la mécanique céleste, Gauthier-Villars, 1983.

Rullani E., L'impresa come sistema artificiale: linguaggio e apprendimento nell'approccio evolutivo alla complessità, in Economia e Politica Industriale, n. 56, 1987.

Rullani E., La teoria dell'impresa: soggetti, sistemi, evoluzione, in Rispoli M., (ed.), L'impresa industriale. Economia, tecnologia, management, Il Mulino, 1989.

Rullani E., Vicari S. (ed.), Sistemi ed evoluzione nel management, Etas, 1999.

Ruozi R., L'evoluzione del sistema finanziario italiano attraverso l'attività di Newfin, intervento al Convegno Newfin sul tema Banche e mercati mobiliari, Università Bocconi, 18 settembre 1995.

Saraceno P., Il governo delle aziende, Libreria Universitaria Editrice, 1972.

Sciarelli S., Il governo dell'impresa in una società complessa, in Sinergie - Rivista di Studi e Ricerche, n. 45, 1998.

Tagliagambe S., Usai G., L'impresa tra ipotesi, miti e realtà, Isedi, 1994.

Vaccà S., L'economia delle relazioni tra imprese: dall'espansione dimensionale allo sviluppo per reti esterne, in Economia e politica industriale, n. 51, 1986.

Vallini C., Fondamenti di governo e di direzione d'impresa. Fasc. I: L'impresa reale e la sua teleologia, Giappichelli, 1990.

Varaldo R. (ed.), Ristrutturazioni industriali e rapporti fra imprese, F. Angeli, 1979.

Vicari S., L'impresa vivente. Etas, 1991.

von Bertalanffy L., General System Theory, George Braziller, 1968.

von Foerster H., Sistemi che osservano, Astrolabio, 1987.

Weick K., The Social Psychology of Organizing, Random House, 1979.

Wiener N., Cybernetics, MIT Press, 1948.

${ }^{1}$ For a detailed analysis of the concept of the systemic approach to the firm see Golinelli GM., L'approccio sistemico al governo dell'impresa. I - L'impresa sistema vitale, Cedam, 2000.

${ }^{2}$ In respect of this profile, any metric used to measure the performance of the firm system can only refer to the structure of the firm.

${ }^{3}$ The concept of openness is a central element in the systemic approach. It has a relative connotation indeed a system can be classified as open or closed in relation to a certain supra-systems and to the relationships and interactions established with them.

The openness varies in term of time and space, in relation to the government decisions and its ability to understand individual supra-systems; considering carefully the systemic scope and the connection that can be established with the reference systems. The relevance of the concept of openness emerges, during the development of the inter-systemic relationships.

4 The concepts of 'consonance' and 'resonance' will find appropriate clarification in the following work. 
${ }^{5}$ An example is the level of available technologies during the phase of development of the physical structure and of the other external organizations, more or less advanced.

${ }^{6}$ See Beer S., Brain of the Firm. The Managerial Cybernetics of Organization, The Penguin Press, 1972.

7 The viability of the firm system requires an activity of government able to identify: the uncertainty of the future, a predominance of the variety of possible states of the structure and assuming, consciously, decisions with the scope to become systemic and to survive

${ }^{8}$ See Beer. Diagnosing the system for organization, John Wiley, 1985. The term viable means: Able to Maintain a separate existence (Oxford English Dictionary).

${ }^{9}$ Obviously, it is possible to hypothesize viable systems in which one of the areas may appear very small compared to the other.

${ }^{10}$ Please note that, instead, it is certainly possible to study the characteristic of the system X, regardless of supra and sub-systems.

${ }^{11}$ In regard, cf. Italian stock exchange, Codice di autoregolazione, http: \\www.borsaitalia.it $\backslash 9 \backslash$ $122 \backslash 218 . h t m l, 1999$.

${ }^{12}$ The demonstration was taken from A. Lanza, Knowledge Governance, EGEA, 2000, p. 135 et seq. 